\title{
Resilience of a Territory: Concept, Measurement, Governance
}

\author{
B. S. Zhikharevich ${ }^{a, b}, *$, V. V. Klimanov ${ }^{c, d, * *}$, and V. G. Maracha ${ }^{c, e, * * *}$ \\ ${ }^{a}$ Institute of Regional Economics Studies, Russian Academy of Sciences, St. Petersburg, 190013 Russia \\ ${ }^{b}$ International Center for Social and Economic Research “Leontief Center," St. Petersburg, 199005 Russia \\ ${ }^{c}$ Russian Presidential Academy of National Economy and Public Administration, Moscow, 119571 Russia \\ ${ }^{d}$ Institute for Public Finance Reform, Moscow, 125009 Russia \\ ${ }^{e}$ Financial University under the Government of the Russian Federation, Moscow, 125993 Russia \\ *e-mail: zhikh@leontief.ru \\ **e-mail:vvk@irof.ru \\ ***e-mail: maratcha@yandex.ru
}

Received July 18, 2020; revised October 19, 2020; accepted October 21, 2020

\begin{abstract}
The paper considers problems of adequate interpretation of the term resilience in relation to the term sustainable development and offers a consistent holistic system of concepts based on the term shock resistance (shokoustoichivost'), which allows to discuss the problems of sustainable development and resilience (without mixing these terms). The directions for creating a methodology for measuring resilience are proposed, based on a study of theoretical and methodological approaches and existing attempts to measure the resilience of cities and regions. The article describes existing Russian examples of measuring the resilience of regions a posteriori (by analyzing the behavior of indicators of socioeconomic development during and after economic and budgetary crises) and a priori (based on the characteristics of industry structure or risk resistance of the economic, social, and governance subsystems of a region). A paradox is noted: in Russia, subsidization of a region and a backward structure of the economy are factors that increase resilience. Ways are shown to embed mechanisms for increasing resilience in the strategic governance system of urban and regional development. It is proposed to introduce resilience auditing into management practice and create a regional (municipal) risk-management system and the position of a risk manager.
\end{abstract}

Keywords: resilience, shock resistance, viability, vitality, risk, city, region, strategic governance, sustainable development

DOI: $10.1134 /$ S2079970521010135

\section{INTRODUCTION AND FORMULATION OF THE PROBLEM}

The increasing frequency of various shocks (crises, disturbances, man-made accidents, etc.) against accelerating technological development has naturally honed the interest in studying the phenomena of reaction to shocks, the ability to cope with them, and recover from natural and other disasters. In the English-language scientific and consulting literature, concepts began to be actively developed and consulting services offered, including such terms as resilience, regeneration, revitalisation, and vitality, used in relation to enterprises and industries, as well as cities, regions, and countries. The term resilience is frequently used, e.g., the European Urban Resilience Forum. One renowned author and popular consultant in this field, Storm Cunningham ${ }^{1}$, created and heads the Reconomics Institute, characterized as the Society of Revitalization \& Resilience Professionals, publishes

\footnotetext{
${ }^{1}$ https://stormcunningham.com.
}

Revitalization: The Journal of Urban, Rural \& Environmental Resilience, and wrote three books, the last being Reconomics: The Path to Resilient Prosperity [17].

The actual ability of the system to maintain its current state under the influence of external impacts is studied in different sciences: from mechanics to sociology. For economic systems, this topic has become very important over the past decade. Following the 2008-2009 crisis, studies on resilience in relation to regions began to appear. In 2010, a special issue of Cambridge Journal of Regions, Economy and Society was published [15].

In Russia, an adequate interpretation of the terms used in this area and understanding of the concepts based on them are complicated by difficulties of translation into Russian. The most suitable Russian word for the meaning of the word resilience (originally in materials science-elasticity, the ability to return to the original state after exposure) would be the word ustoichivost' - the ability to resist, to withstand blows, to survive and recover. This is exactly how the main 
dictionaries and automatic translators translate the word. But ustoichivost' in relation to countries and regions is already strongly associated with the concept of sustainable development. Therefore, to translate the resilience, either the loan translation rezilientnost' [6] is used, or such variants as zhiznestoikost' (vitality) [24], zhiznesposobnost' (viability), zhivuchest' (survivability), antikhrupkost' (antifragility), or just ustoichivost'. Following the selected word, authors include various nuances in the interpretation, narrowing, or expanding the original concepts.

In connection with the above, the following tasks of this article are relevant:

(1) to create, based on term resilience, a consistent integral system of concepts for discussing problems of sustainable development and resilience in Russian and provide an adequate translation of the corresponding English terms;

(2) based on a study of theoretical and methodological approaches and existing attempts to measure the resilience of cities and regions, to suggest directions for creating techniques for measuring resilience;

(3) to outline the ways of embedding mechanisms for increasing resilience into the strategic governance system for development of cities and regions.

\section{CONCEPT: WHAT IS RESILIENCE?}

Let us attempt a holistic approach to defining the set of terms used to study the issues of sustainable development and shock resistance, the features of which are: (a) applicability primarily to territorial objects (cities, regions) considered as territorial communities or territorial socioeconomic systems (TSES); (b) orientation toward use in the practice of governance, (c) reliance on cybernetics and a systems approach.

As the main translation variant for resilience, we suggest using the word shokoustoichivost' (shock resistance). First, the term itself is intuitively clear and is already a definition of the characteristic property of the system - the ability to adequately respond to external disturbing influences. Second, it clearly differs from plain ustoichivost', which has a broader understanding. Third, one can still use the term zhiznesposobnost' (viability) to characterize even more general properties of the system. A literal translation-uprugost' (elasticity) - does not fit well with socioeconomic terminology. The loan translation rezilientnost' is dissonant and devoid of intuitive meaning.

A careful interpretation of the resilience concept was developed at Argonne National Laboratory, which proposed its own definition: "The ability of an entity-asset, organization, community, region-to anticipate, resist, absorb, respond to, adapt to, and recover from a disturbance" [16, p. 17].

A peculiarity is that the definition includes the components of resilience associated with actions both before and after the shock. The first three components (anticipate, resist, absorb) prevent or mitigate the shock to an insignificant level (e.g., predict seasonal illness and vaccinate the population). The next three relate to what happens after a shock-response actions that includes an immediate response and adaptation, then a return to the old or new norm (e.g., after the outbreak of a pandemic, deploy the health care reserve capacity, establish quarantines, develop a vaccine, then return to normal health care regimes, possibly by changing the standards of epidemiological safety).

Materials of the Arctic council define resilience somewhat differently: "The capacity to cope with stress and shocks by responding or reorganizing in ways that maintain essential identity, function, and structures, as well as the capacity to navigate and shape change, including transformational change" $[13$, p. XVII]. Here the emphasis is not on actions, but on the ability of a system to persist and change. However, in both definitions, the words shock, stress, and disturbing effect are primary, e.g., relatively shortterm and strong effects.

The system of definitions with respect to territorial socioeconomic systems (regions and cities) may look as follows.

Resilience of a TSES-the ability of a TSES to withstand shocks, including the ability to anticipate, prevent, resist, absorb, react, adapt, and recover, including the ability to return to the trajectory of sustainable development with the smallest losses after relatively short-term natural, man-made, economic, social, and financial shocks.

Vitality of a TSES-the life force of a TSES, the ability of the system to keep system-forming qualities in any conditions, maintaining key socioeconomic characteristics in an acceptable range of values due to its high shock resistance.

Development sustainability of a TSES-the ability of a TSES to be on the trajectory of sustainable development over a long time period.

Sustainable development of a TSES-development while maintaining a balance between the interests of present and future generations in resource use and with orientation toward the United Nations 17 sustainable development goals. In this case, in our opinion, it would be more correct to use the concept of balanced development.

Long-term viability of a TSES-the ability of a TSES, developing under conditions of uncertainty, to remain on the trajectory of sustainable development with minimal deviations, constantly adapting to changes.

Resilience can vary in the emphasis on measures before the shock (preventive resilience) or on actions after the shock (recovery shock resistance). Moreover, the recovery can be varied: to the initial state or a new sustainable state. A TSES with a high potential for resilience primarily prevents or reduces the likelihood 
of shocks due to constant risk monitoring can withstand or immediately absorb (and sometimes turn to its advantage) low-level shocks. And if a shock event did occur, it can react quickly and efficiently with minimal losses and return to its original state, or change and switch to a new trajectory, preserved as a whole.

Resilience in this set of definitions is a characterization of the properties of a system, the antipode of vulnerability, while sustainability is a characterization of its development. Sustainable development of a TSES presupposes the presence of many properties, among which is also shock resistance.

The proposed hierarchy of concepts, resiliencevitality-sustainability - viability, is not the only possible one. For example, N.Yu. Zamyatina is inclined to interpret resilience more broadly, believing that "...the study of sustainability, with the transition from the concept of sustainable development to the resilience has been experiencing a research boom in recent years" [3, p. 2]. We believe that resilience (no matter how we translate this term) does not replace sustainable development; we suggest placing it at the bottom of the hierarchy. As N.Yu. Zamyatina et al. emphasize [4], "The concept of sustainable development is focused on the study of the stability of the object of study in relatively stable conditions, while the concept of resilience is developed in terms of shock effects." Meanwhile, long-term viability appears at the top of the hierarchy-a concept that goes back to the founder of organizational cybernetics, S. Beer [14], and is more general than sustainability or sustainable development. Sustainable development is now more in the hands of politicians than scientists while maintaining its ecological heritage. Therefore, we consider it important to have long-term viability in the attention field of TSES researchers, recognizing that the borderline between it and sustainable development is now more dotted than solid. There is also a dotted line between resilience and shock resistance. However, between the pairs "long-term viability-sustainable development" and "resilience-shock resistance", there are quite definite and distinct differences with important implications for governance practice.

Resilience can be studied and evaluated in relation to different types of shocks. Shocks can differ (a) by nature-natural, man-made, economic, financial, social; (b) by the strength and probability of shocks. There are authors who propose speaking about shock resistance (or resilience) only in relation to shocks (failures) with low probability and severe consequences [12].

In Russian-language scientific periodicals, the first quantitative studies of regional resilience were published by V.V. Klimanov et al. [6-8]. In the proposed system of terms, they relate to the measurement of recovery the economic (and fiscal) resilience of Russian regions, i.e., the ability to recover from economic crises. Here, the term rezilientnost' is used.

\section{QUANTITATIVE ESTIMATES OF RESILIENCE: AN APPROACH}

Turning to the applied aspects of resilience (can this property of TSES be measured and controlled), let us return to the seven main components of shock resistance, which can be characterized qualitatively and quantitatively.

The ability to anticipate and prevent shocks presupposes a monitoring and defense system (e.g., monitoring the water level in the Gulf of Finland or control at the airport entrance).

The ability to resist and absorb means the readiness for a quick response to threatening events (a dam preventing the shock of the flooding of St. Petersburg, or an intercept group that detects and neutralizes potential terrorists).

The ability to react means the readiness of the control system and specialized services to participate in the immediate elimination of the shock consequences and combat the spread of consequences-extinguishing fires, evacuating people, creating anti-crisis headquarters.

The ability to adapt presupposes a willingness to promptly start mitigation measures: resettlement of victims, treatment of infected, introduction of quarantine measures, material support.

Lastly, the ability of recovery presupposes the presence of think tanks ready to analyze different options and possibilities of recovery (reconstruction of destroyed structures in their previous form or construction of more efficient ones, relocation of a settlement to another place or its liquidation, return to the previous structure of the economy or change), to choose and effectuate a rational option.

Clearly, each of these components of resilience requires specialists with different competencies and different actions, as well as accordingly, different methods of analysis and systems of indicators for assessing the potential of resilience for this component.

The potential of resilience is higher in TSES where the community can learn from past shocks and create better defenses, reducing the likelihood of new shocks (e.g., the effective response of a number of Asian countries to the COVID-19 pandemic, which have learned a lot from previous viral outbreaks).

In [16], the resilience of a TSES (city, region) is considered as a resilience function of at least five subsystems: economic, civil society and social capital, critical infrastructure, supply chain/dependencies, and governance/institutional. For each subsystem, characteristics and indicators of resilience are proposed. 
Economic Subsystem. The resilience of the economy is characterized by both the volume and variety of resources and equality in their distribution. It depends on the interaction of people, firms, and institutions in the production, distribution, and consumption of products. The following components are used to construct the Resilience Capacity Index for a region: income equality, measured by the Gini coefficient; diversification of the economy in terms of employment structure; housing affordability, measured by the proportion of families spending less than $35 \%$ of their income on housing; business climate, characterized by the share of small businesses, the number of created and liquidated businesses, the prevalence of highspeed Internet, and the size of venture capital.

Civil Society and Social Capital Subsystem. Social resilience is ensured by the presence of informal neighborhood ties between people and between enterprises, communication channels for collecting and disseminating information, forms of mutual assistance, and readiness for joint actions independently of official authorities. The metrics are the following: educational level, level of health (share of the population without disabilities), level of nonpoverty (share of the population with an income above the poverty line), health insurance coverage, civil society infrastructure-the number of nonprofit organizations per 10000 inhabitants, rootedness of the population, home ownership, and electoral activity.

Critical Infrastructure (roads, water supply, communications, energy, healthcare, etc.). The infrastructure resilience of a TSES is characterized by the presence of infrastructure and the ability of its owners and managers to ensure operation in emergency situations. It is essential to have a reserve housing stock and hospitals, reserve sources of electricity and water supply, and redundant communication channels.

Supply Chain/Dependencies Subsystem. Resilience here is determined by the ability of supply chain operators to ensure interaction with partners, as well as the availability of reserve stocks, the flexibility of enterprises in preparedness for trouble, and the number of links and nodes in the supply chain, and their connections and location in a territory. Of great importance is the interaction of enterprises with the authorities in the exchange of information and the establishment of legal norms, contracts, forms of cooperation.

Governance/Institutional Subsystem. Resilience of the state (municipal) governance system depends on the ability of the territorial community to attract local residents and enterprises to mitigate the consequences of a shock, create organizational ties, and support local social systems; the capacity for interdepartmental interaction, trust in the authorities, adequacy of the authorities' powers in the face of shocks, the volume and effectiveness of budget expenditures on ensuring security and the activities of the relevant emergency services are important.
Based on the considered characterization of resilience for each subsystem, we can try to select quantitative indicators. The experience of the United States provides a certain reference point here, but, of course, for Russia's realities, it is possible to choose indicators from a different set provided by state statistics and special studies.

The need to use the same limited set of indicators from state regional statistics leads to unavoidable simplifications and compromises.

\section{QUANTITATIVE ESTIMATES OF RESILIENCE: EXAMPLES FROM RUSSIAN PRACTICE}

In Russian practice, there are few examples of calculating indicators related to regional resiliance.

The study by V.V. Klimanov, S.M. Kazakova, and A.A. Mikhaylova features a scientific approach [7] based on an assessing the resilience level of federal subjects (regions) using the adapted methodology for calculating the Resilience Capacity Index developed by K. Foster [18] and used in many studies [20].

The authors compiled a database of 17 indicators reflecting the complex socioeconomic development of federal subjects. For a given sampling for each region, an integral Resilience Capacity Index was calculated for the time period of 2007-2016. The group of nonresilient regions includes mainly subjects of the Southern, North Caucasian, Siberian, and Far Eastern federal districts (macroregions). Significant differences were found in the dynamics of indicators in different periods.

The grouping was refined by the same authors in [8], depending on the parameters characterizing the accumulated potential of the regions, their current state, and the dynamics of development. The identified two main groups of regions were divided into subgroups, for each of which the trajectories of individual indicators were calculated. The criteria for resilience consisted not only of the average index for 2007-2016, but also the specific values of this indicator per year after the onset of the crisis.

Thus, in this case, resilience is measured integrally and a posteriori (after a shock) by studying the depth of fall and recovery rate of individual indicators after an economic shock.

Among the approaches used by rating agencies and consulting firms, we consider two that assess resilience a priori.

The Rating of Russian agglomerations by the degree of resilience to the 2020 crisis developed by the consulting company MACON [10] is based on two parameters: (a) the sectoral structure of the urban agglomeration economy and (b) expert assessment of each urban sector, depending on its vulnerability, recovery rate, and predicted consequences. The assessment was made in relation to the specific circumstances of the 2020 crisis on a scale from 0 to 1 , where 1 is the greatest 
stability and 0 is the least (up to complete or temporary liquidation of a sector). Thus, the resilience of tourism and trade was estimated at 0.1 ; construction- 0.5 ; and communal sevices-0.8.

The sum of sectoral assessments, weighted by the share of the sector in the structure of the economy, is interpreted as an integral assessment of the potential resilience for the urban agglomeration. Accordingly, agglomerations are more resilient (e.g., Perm, Chelyabinsk, and Saratov) where there is a high share of industries (local non-market services, manufacturing, and public utilities) likely to be supported by the authorities; the least stable are urban agglomerations (Moscow, St. Petersburg, Krasnodar, Yekaterinburg) with a progressive structure of the economy, characterized by a high share of market services, which are both more vulnerable and less frequently supported.

The conclusions are paradoxical only at first glance, since in many cases it is true that the simpler the system, the stronger it is. Urban agglomerations with a large share of financial and business services, a developed construction market, and IT technologies risk finding themselves in a more difficult situation than urban agglomerations with a simple and backward structure. It is curious that a significant inverse correlation was revealed between the resilience rating and value of the gross urban product per capita: the poorer the agglomeration, the more resilient it is in the current crisis. Willingly or unwillingly, the state, helping the weak in a crisis (which is natural), encourages conservatism and poverty.

Similar conclusions were previously obtained in relation to a federal subject's level of subsidies [5]: analysis of the 2008 crisis showed that the higher the share of intergovernmental grants in regional budget revenues, the less it experienced a decrease in the main indicators based on the results of 2009 and 2010.

An obvious drawback of this method of measuring resilience is its sectoral basis: it presupposes that the resilience of an urban agglomeration is predetermined by the set of existing industries and the sectoral characteristics of shock resistance. The factors of the quality of local governance, local mentality, local budget, and public activity are ignored, although most likely, they are significant and for the same set of sectors, a TSES will react differently to shocks depending on the mentioned factors.

This drawback has been partially overcome by the company RAEX [11] when compiling the Rating of Russian regions in the management of environmental, social, and governance risks (ESG-rating).

ESG-ratings assess both the level of risk exposure and effectiveness of countering it in the three mentioned subsystems. For each negative indicator, a positive pair is selected-an indicator that reflects how the region is coping with risks. For example, when assessing environmental risk, the pair for the indicator "Emission of pollutants into the atmosphere" will be the "Share of captured and neutralized air pollutants". In theory, the higher the first indicator, the higher the second. The presence of an imbalance indicates that risks are not given due attention.

In the 2020 ranking, the leading regions were where high budget revenues, together with a good investment climate, make it possible to maintain high social standards and where environmental risks are mitigated by the efforts of local authorities and businesses. The Republic of Tatarstan, Moscow, and Lipetsk oblast are in the top three of the rating. The imbalance of the components of the final rating are noteworthy: a high place in one of the three components is accompanied by low places in the other two.

Without going into the calculation technique, we note that the results, as with any rating, depend on the selected indicators and their weighting, and in this case, on expert assessment of balance/imbalance in pairs of indicators. The set of indicators used for the Russian rating (see [1]) does not fully ensure compliance with the general methodology of this type of ratings declared by the compilers, which focuses on the needs of investors and involves assessment of a wide range of properties and characteristics [19]. This, in the Environment section, the existence of environmental programs, their quality, and the volume of expenditures on environmental activities should be taken into account. In the Social section, it is necessary to analyze the state of social sectors (social benefits, education, health care, and security), as well as take into account the development of corporate social responsibility forms and the ability of the population to participate in direct financing of projects and the development of public-private partnerships. The Governance section ideally involves analysis of political risks and the population's level of support for the government, investment attractiveness and business support instruments; it takes into account the degree of governance transparency and the level of corruption, as well as the quality of budget management.

The methodology of the ESG-rating is close to the approach of the Argonne National Laboratory, i.e., oriented toward assessing the readiness of individual TSES subsystems to overcome shocks. It can be considered the first approximation to the methodology for assessing resilience in Russia.

In Russia, resilience is traditionally understood from the standpoint of not just confronting risks and vulnerability, but also security. If we talk about nonmilitary types of security, then EMERCOM of Russia is primarily responsible for them, which covers only a limited range of security kinds. The Ministry of Energy of the Russian Federation has its "own" security and its own Energy Security Doctrine. There, special schemes have been developed for compensation measures in the event of disruption threat to the energy infrastructure. There is also a Food Security Doctrine. In terms of governance, all these types of security are 
provided in mobilization logic based on schemes previously approved for different levels of governance. A feature of mobilization schemes is the quality, unseen in civilian life, of interagency and inter-level coordination and the speed of problem resolution. This also applies to the deployment of medical infrastructure to combat the COVID-19 pandemic (but not economic assistance!). To combat the COVID-19 pandemic in Russia at the highest level, two coordination councils were created, but solving economic issues still required a personal decision from the President of the Russian Federation. Therefore, the Governance section of the resilience rating should include criteria that characterize the ability of authorities to quickly switch to operating in mobilization mode, as well as the presence of predeveloped schemes and mechanisms for operating in such a mode.

\section{RESILIENCE GOVERNANCE}

Knowing the characteristics of TSES associated with its resilience, and the ability to measure them makes it possible to manage resilience as a conscious impact on the identified characteristics, taking into account the available resources and relationships. Analysis and assessment of the TSES resilience is an important element that should be integrated into the development governance system.

Studies by the above-mentioned S. Cunningham promote the idea of the possibility and need to simultaneously achieve postcrisis recovery, economic growth, and resilience of the local community, which triples the effect of investments in economic renewal/recovery. The concept of reconomics introduced by this author entails the set of processes leading to a resilience recovery and renewal of cities and regions. These processes are guided by recovery strategies and programs that repurpose, renew, and restructure relationships between engineering, natural, social, and economic assets. As a result, local authorities obtain a tool for long-term viability by combining previously disparate policies with a singular meaning.

The author's advices are not particularly new: he recommends approaching development in an integrated manner, e.g., when implementing projects to renovate a city center and restore historical heritage, keep in mind processes such as strengthening infrastructure, caring for air quality, and reclaiming natural resources. This, it is critically important to create a holistic reconomic process rather than a set of disparate projects, for each of which a separate new partnership is usually formed and its own stakeholders recruited. The holistic strategizing process and planning with the involvement of all stakeholders [9] will provide constant movement and efficiency, giving the main effect: confidence in the future of the local community.
Important difference from standard recommendations for territorial strategic planning in the fact that it is not just about development, but about development as a process of constant renewal (rapidly aging assets), taking into account resilience.

The ability to manage the TSES development to strive simultaneously toward an increase in both sustainability and resilience does not negate the importance of distinguishing between these properties. The actions that a territorial community must take to achieve sustainable development are not always the same ones necessary to increase resilience. Fortunately, there is a nonempty set of invariant actions that simultaneously increase both sustainability and resilience, contributing to long-term viability (see Table 1).

Undoubtedly, in strategic planning, it is necessary to pay special attention to the qualities of a region (city) that increase the resilience of its subsystems: economic diversification, ecosystem of entrepreneurship, security, reliability of infrastructure, environmental protection, and social capital. It seems that resilience is higher where the quality of governance in general is higher, there is more social capital (cohesion of society) and cooperation capital (cohesion of stakeholders), where the population is smarter, healthier, and more reasonable, where appropriate plans/strategies (security strategies) and antishock protocols/instructions are developed and approved (both in the EMERCOM of Russia and in the economy), where the infrastructure is less depleted, and the environmental parameters are under reliable control.

It would be useful in the future to statistically check these intuitive ideas about resilience factors.

The concept of resilience can also be applied to strategic planning documents, in two aspects: how resilience issues are taken into account in strategies and how resilient the strategies themselves are (see Table 2). This sets guidelines for improving the strategic planning of territorial development.

\section{CONCLUSIONS}

(1) It is necessary to distinguish between the concepts of sustainability and resilience. Using one the term sustainability to convey the meaning of the concepts of sustainable development (presupposing a longterm balance of economic, social, and natural subsystems) and resilience (in the sense of being able to withstand short-term shocks) is unproductive. A too broad interpretation of the concept of sustainability without isolation of resilience is rather a weak point in Russia's public administration system. This is possibly one of the deepest reasons for the lack of preparedness for the 2020 crisis and the delay in adopting anti-crisis measures.

(2) The methodology for measuring resilience can be based on the Argonne National Laboratory 
Table 1. Factors, tools, and mechanisms for increasing long-term viability and resilience of TSES

Factors, tools, and mechanisms for increasing

\begin{tabular}{|c|c|}
\hline long-term viability & resilience \\
\hline $\begin{array}{l}\text { Development of education } \\
\text { Health promotion } \\
\text { Spiritual and moral education } \\
\text { Diversification of the economy } \\
\text { Development of entrepreneurship, maintaining ecosystem } \\
\text { of entrepreneurship } \\
\text { Building social capital, citizen cohesion, civil society, social } \\
\text { ties, local patriotism } \\
\text { Building cooperative capital, capacity of local stakeholders } \\
\text { for joint action } \\
\text { Environmental pollution control } \\
\text { Environmental education } \\
\text { Resource saving }\end{array}$ & $\begin{array}{l}\text { Development of antishock protocols, evacuation plans, } \\
\text { strategies and programs (including for economic block of } \\
\text { governance) } \\
\text { Creation of reserves, inventories, duplication of life-support } \\
\text { systems, creation of reserve hospitals } \\
\text { Use of risk management in public administration practice } \\
\text { Regularly conduct resilience audits } \\
\text { State and municipal property insurance } \\
\text { Maintaining good-neighborly interregional and intermu- } \\
\text { nicipal relations of mutual assistance } \\
\text { Building relationships with central authorities making it } \\
\text { possible to count on assistance }\end{array}$ \\
\hline
\end{tabular}

Source: compiled by the authors.

Table 2. Resilience and strategic planning

\begin{tabular}{|c|c|}
\hline Strategic plans of resilience & Resilience strategic plans \\
\hline $\begin{array}{l}\text { Strategic plans that increase TSES resilience: } \\
\text { pay special attention to the sections Threats and Weaknesses } \\
\text { when conducting SWOT Analysis; } \\
\text { contain a section with risk analysis; } \\
\text { contain a large set of well-developed, including anticrisis, } \\
\text { scenarios; } \\
\text { propose the creation of a regional/municipal risk-manage- } \\
\text { ment system and the position of a risk manager, integrated } \\
\text { into the strategy implementation management system; } \\
\text { contain a well-developed Security section with a list of nec- } \\
\text { essary crisis protocols. }\end{array}$ & $\begin{array}{l}\text { Resilience TSES strategic plans are "live" strategies: } \\
\text { easily adjustable, with an unchanged core of meanings and } \\
\text { goals and a block of variable indicators; } \\
\text { have a well-developed strategy implementation manage- } \\
\text { ment system built in organizational cybernetics logic (mon- } \\
\text { itoring-control-evaluation -correction and change } \\
\text { management); } \\
\text { containing a calculation model for linking and forecasting } \\
\text { indicators; } \\
\text { managed by a permanent professional team; } \\
\text { supported by stakeholders. }\end{array}$ \\
\hline
\end{tabular}

Source: compiled by the authors.

approach, which presupposes an assessment of at least five TSES subsystems (economy, society, infrastructure, supply chains, governance) in the context of seven components of resilience (anticipation, prevention, resistance, absorption, response, adaptation, and recovery). When selecting indicators, the experience of developing the first ratings and groupings of Russian regions in terms of risk management, degree of resilience, and others is useful.

(3) For governance purposes, it is useful to learn how to measure a priori resilience with respect to different types of shocks, at least on a point scale.

(4) An urgent scientific problem is the search for the possibility of verifying hypotheses about resilience factors by comparing a priori and a posteriori assessments. To develop practical recommendations, it is important to identify the relationships between the behavior of socioeconomic development indicators during crises with the properties of TSES that increase resilience.

It is paradoxical that in Russia the factors of increasing the region resilience are the subsidization of the region and the backwardness of the economy structure, and not the quality of public administration in the region.

(5) Strategic planning should pay attention to problems of increasing resilience, for which it is useful to: improve the quality of studying the sections Threats and Weaknesses when conducting SWOT Analysis; use risk analysis methods; develop a wider range of scenarios, including anti-crisis ones; study the section Security, including proposals for the catalog of necessary crisis protocols; include in the task system the creation of a regional/municipal risk management system and the position of a risk manager, integrated into the strategy implementation management system. 
(6) A resilience audit should be part of the strategic analysis. When forming strategic directions, goals, and objectives, it is useful to take into account the interrelationships between development processes, recovery after inevitable shocks, renewal, and increase in resilience.

\section{CONFLICT OFINTEREST}

The authors declare no conflict of interest.

\section{REFERENCES}

1. ESG-rating of Russian regions: compilation method, RAEX Rating Review. https://www.raex-rr.com/methods/97. Accessed July 17, 2020.

2. Vazhenin, S.G. and Vazhenina, I.S., Resilience of territories in a competitive economic space, Reg.: Ekon. Sotsiol., 2015, no. 2 (86), pp. 175-199.

3. Zamyatina, N.Yu., Sustainable variability: features of Russian Arctic cities and assessment of their resilience, Meridian, 2019, no. 2 (20), pp. 123-125. https:// www.meridian-journal.ru/site/article?id=1221. Accessed July 17, 2020.

4. Zamyatina, N.Yu., Medvedkov, A.A., Polyachenko, A.E., and Shamalo, I.A., Resilience of Arctic cities: an analysis of approaches, Vestn. S.-Peterb. Univ., Nauki Zemle, 2020, vol. 65 , no. 3 . https://doi.org/10.21638/spbu07.2020.305

5. Kazakova, S.M. and Mikhailova, A.A., Subsidies as a factor in the sustainability of regional economic systems, Ross. Ekon. Zh., 2018, no. 2, pp. 29-37.

6. Klimanov, V.V., Kazakova, S.M., and Mikhailova, A.A., Theory of regional resilience, Ekon. Polit., 2018, vol. 13, no. 6, pp. $164-187$.

7. Klimanov, V.V., Kazakova, S.M., and Mikhailova, A.A., Retrospective analysis of the resilience of Russian regions as socioeconomic systems, Vopr. Ekon., 2019, no. 5, pp. 4664.

8. Klimanov, V., Kazakova, S., Mikhaylova, A., Safina, A. Fiscal resilience of Russia's regions in the face of COVID-19, J. Publ. Budg. Account. Finan. Manag., 2020.

https://doi.org/10.1108/JPBAFM-07-2020-0123
9. Maracha, V.G., Regional strategic planning: basic approaches and conditions for implementation, Probl. Teor. Prakt. Upr., 2008, no. 11, pp. 35-42.

10. Rating of Russian agglomerations by the resistance to crisis in 2020. https://www.macon-realty.ru/publications/CommentsAndPredictions/reyting_rossiyskih aglomeraciy_po_stepeni_ustoychivosti_k_krizisnym_ yavleniyam_v_2020_godu. Accessed July 17, 2020.

11. Resilience as the norm of life, ESG rating of Russian regions, RAEX Rating Review. https://www.raex-rr. com/country/ESG_rating_regions?. Accessed July 17, 2020 .

12. Sheffi, Y., The Resilient Enterprise: Overcoming Vulnerability for Competitive Advantage, Cambridge, MA: MIT Press, 2005.

13. Arctic Council Arctic Resilience Report, Carson, M. and Peterson, G., Eds., Stockholm: Stockholm Eviron. Inst., 2016. https://www.arctic-council.org/arr. Accessed July 17, 2020.

14. Beer, S., Brain of the Firm: A Development in Management Cybernetics, London: Penguin, 1972.

15. Cambridge J. Reg., Econ. Soc., 2010, vol. 3. https://www.academic.oup.com/cjres/issue/3/1. Accessed July 17, 2020.

16. Carlson, J.L., Haffenden, R., Bassett, G., Buehring, W.A., Collins, M.J., Folga, S.M., Petit, F., Phillips, J.K., Verner, D., and Whitfield, R.G., Resilience: Theory and Application, Argonne, IL, Argonne Natl. Lab., 2012. https://doi.org/10.2172/1044521

17. Cunningham, S., Reconomics: the path to resilient prosperity, 2020. https://www.stormcunningham.com. Accessed July 17, 2020.

18. Foster, K.A., A Case Study Approach to Understanding Regional Resilience: Working Paper 2007-08, Berkeley: Univ. of Calif., 2007. https://www.econstor.eu/bitstream/10419/59413/1/592535347.pdf. Accessed July 17, 2020.

19. Methodology for assigning ESG ratings to regions: short public version. https://www.raexpert.eu/ files/methodology/Methodology_ESG_Region.pdf. Accessed July 17, 2020.

20. Pendall, R., Foster, K.A., and Cowell, M., Resilience and Regions: Building Understanding of the Metaphor, Berkeley: Univ. of Calif., 2007.

https://www.iurd.berkeley.edu/wp/2007-12.pdf. Accessed July 17, 2020. 